\title{
ResearchOnline@JCU
}

This is the author-created version of the following work:

Lloyd, Janice, Tzioumis, Vicky, Freire, Rafael, Hood, Jeni, Philips, Clive J.C.,

Johnson, A. Jane, and McGreevy, Paul D. (2018) Educators' perspectives on animal welfare and ethics in the Australian and New Zealand veterinary curricula. Journal of Veterinary Medical Education, 45 (4) pp. 448-463.

Access to this file is available from:

https://researchonline.jcu.edu.au/48510/

Please refer to the original source for the final version of this work: 


\section{Educators' perspectives on animal welfare and ethics in the Australian and New Zealand} veterinary curricula.

Vicky Tzioumis, Rafael Freire, Jennifer Hood, A Jane Johnson, Janice Lloyd, Clive J C Phillips, Paul D McGreevy

Rafael Freire, School of Animal and Veterinary Science, Charles Sturt University - Sutherland Laboratories, Wagga Wagga NSW 2650, Australia; PhD; Lecturer; animal behaviour and welfare

Jennifer Hood, Faculty of Veterinary Science, University of Sydney, NSW 2006, Australia; $\mathrm{PhD}$; Research Officer Veterinary Science; animal welfare, ethics, and regulatory compliance

A Jane Johnson, Faculty of Veterinary Science, University of Sydney, NSW 2006 Australia; $\mathrm{PhD}$; Academic Coordinator, applied ethics (particularly animal ethics, ethics of surgical innovation and bioethics)

Janice Lloyd, College of Public Health, Medical and Veterinary Science, James Cook University; 1 James Cook Drive, Townsville City QLD 4811, Australia; PhD; Senior Lecturer; animal behaviour and welfare

Clive J C Phillips, School of Veterinary Science, University of Queensland, Gatton QLD 4343, Australia; $\mathrm{PhD}$; Professor and inaugural holder of the Chair in Animal Welfare; animal welfare

Paul D McGreevy, Faculty of Veterinary Science, University of Sydney, NSW 2006, Australia; $\mathrm{PhD}$; Professor and Sub-Dean Animal Welfare; animal behaviour and animal welfare science Primary author and email address to whom correspondence should be addressed: vicky.tzioumis@sydney.edu.au 


\section{Abstract}

The current study was designed to explore the importance veterinary science educators in Australian and New Zealand universities assign to animal welfare and ethics (AWE) topics as Day One/initial competences for new graduates. An online questionnaire was deployed in parallel to an equivalent study of veterinary science students at these educators' schools. Responses were received from 142 educators ( $51 \%$ females $n=72$ and $49 \%$ males $n=70$ ), representing an overall participation rate of $25 \%$. Questions were clustered according to seven areas of veterinary employment: General Practice; Production Animals; Companion Animals; Wild Animals; Aquatic Animals; Animals Kept for Scientific Purposes; and Animals Used in Sport and Recreation. The most highly rated topics for each of these clusters were: professional ethics in General Practice; euthanasia in Companion Animals; strategies to address painful husbandry procedures in Production Animals; Veterinarians' duties to wild animals in Animals in the Wild; aquatic animal health and welfare issues in Aquatic Animals; competence in the 3Rs (replacement, refinement and reduction) in Animals kept for Scientific Purposes and responsibilities of ownership in Sport and Recreation. Female educators rated many of the topics as significantly more important than did their male counterparts. Educators teaching one or more ethics-related subjects were less likely to rate neutering and euthanasia as important than those not teaching these subjects. The educators' focus on practical issues clashes with a perceived need for veterinarians to actively embrace animal ethics. Overall, the perspectives of these educators should be carefully considered as they are likely to influence student attitudes.

Keywords; animal welfare; ethics; sentience; One Welfare

\section{Introduction}

Veterinary curricula reflect societal use of animals and public interest in their welfare, and can have a lasting influence on veterinarians' attitudes to animal welfare issues (1) (2) (3). Beyond the formal curricular content, the so-called hidden curricula (including how they are structured and delivered and the priority given to different topics) may all influence the next generation of veterinary students' regard for AWE. Most veterinary educators agree that animal welfare is moderately or very relevant to each of their individual subjects (4). Some veterinary schools 
make a conscious effort to bring animal welfare to the forefront and to play a proactive role in its discussion by society (5).

The inclusion of animal welfare and ethics (AWE) into veterinary curricula is important for several reasons. First, there is growing public interest in AWE (5) (6). Second, there is an increasing impetus from the profession for veterinarians to become leaders in AWE (7), partly because evidence regarding animal sentience means AWE cannot be ignored and also that, arguably, standards of veterinary care are raised by increased awareness of AWE (8). Finally, veterinary programs require accreditation, and accreditation bodies such as the Royal College of Veterinary Surgeons (RCVS) require AWE related skills (9).

Beyond simply including AWE in veterinary curricula, there is a strong argument for prioritising it. After all, veterinarians are professionals with the "ethical responsibility to use their scientific knowledge and skills for the benefit of animal welfare" (10). It has been noted that animal welfare is an issue requiring the veterinary profession to contribute to the debate about animals in ways that would have been unthinkable even ten years ago (11). Speaking up for animals is about to become a core expectation of the veterinary profession, not a "mere side-serving from the brave and detached" (McGreevy, cited by (11).

\section{Attitudes of educators to teaching Animal Welfare and Ethics}

A growing body of research shows attitudes to animal welfare by veterinarians and veterinary students vary and are associated with background, gender, and stage of study (12) (13) (14), (15) (16) (17) (18-21). Arguably, the teaching of animal ethics in veterinary schools is lagging behind the teaching of animal welfare science. Educators teaching veterinary science are also likely to vary in their attitudes to animal welfare, and it is unknown how these variations may affect attitudes and learning in students. For example, studies show that veterinarians may use inadequate pain control in animals (12) (13), and that male veterinarians were less likely than female colleagues to provide adequate analgesia to their patients (12). Thus, feminisation of the veterinary teaching profession (22) may be expected to shift the profession to use adequate analgesia routinely. Additionally, some veterinary educators find themselves in universities where teaching takes place in the overall context of a faculty that is committed to ethical teaching and to maintaining a proactive and public profile on animal welfare issues (5). Under such circumstances, it is reasonable to expect that educators will have an influence over student 
attitudes. By the same token, educators who are dismissive of animal welfare concerns may have a negative influence on the way students prioritise concern for animal welfare. Heleski et al. (23) explored the attitudes of veterinary educators toward farm animal welfare and argued that veterinarians have enormous influence on how farm animals are treated and proposed that graduate attitudes would be influenced by veterinary educators.

Izmirli and Phillips (3) noted that variation in the attitudes of veterinary educators may be influencing students' attitudes to animal welfare, and reported variation in educator's attitudes in different countries. In addition, they found evidence that, even within the same faculty, those teaching clinical subjects had different attitudes to those teaching basic science on topics such as hormonal desexing (neutering) and the use of animals in experiments. Their study raises the possibility that, even within the same course, students may be being exposed to varying and, perhaps even, contrasting opinions on animal welfare. The way in which this influences the development of attitudes to animal welfare in veterinary students is currently unknown. In the current study, we examine, among other things, whether educators teaching different parts of the curriculum differ in their rating of AWE topics.

A first step in understanding the possible influence of veterinary educators' attitudes to animal welfare on student attitudes, is to investigate the current attitudes of veterinary educators. To achieve this, a survey was undertaken as part of an Australian Government Office for Learning and Teaching (OLT) project to develop a shared online AWE teaching resource for veterinary schools in Australia and New Zealand. The aim of the survey was to examine the relative importance veterinary educators place on AWE topics for so-called Day One competences of graduates and to determine if gender and teaching focus affect these ratings.

\section{Materials and Method}

\section{Study Participants}

Veterinary science educators at the eight universities in Australia and New Zealand that deliver a veterinary science degree were invited to participate in the survey in early 2015 . The study received Human Research Ethics Committee approval from the University of Sydney (Approval number: 2014/739). 


\section{The Questionnaire}

Educators were asked to indicate their opinions on the importance of various AWE topics on veterinary graduates' Day One competences, and also to identify their teaching focus. The questionnaire was constructed using the survey system SurveyMonkey ${ }^{\mathrm{TM}}$ (www.surveymonkey.com) and made available online between February and March 2015. A link to the questionnaire was sent to veterinary educators at each of the eight participating universities in a series of three emails asking them to respond to the survey.

The questionnaire comprised 12 questions. Respondents were first asked to consent to participate before answering three demographic questions (university, gender, and stage of course taught) that were single answer multiple choice. The next question asked participants to identify the subjects they taught using a drop-down list from which they were permitted to select multiple answers.

The survey then outlined what the RCVS Day One Competences were and defined what skills and knowledge (competence) Australian and New Zealand veterinary students should expect to have as Day One graduates. The seven questions that followed were assigned to relevant areas of veterinary employment: General Practice; Production Animals; Companion Animals; Wild Animals; Aquatic Animals; Animals Kept for Scientific Purposes; and Animals Used in Sport and Recreation. Each question had number of sub-sections that referred to AWE topics relevant to each area of veterinary employment (e.g., slaughter and pre-slaughter inspections arose under production animals). Each question asked respondents to use a ten-point Likert scale, from extremely important (1) to least important (10), to indicate how important an understanding of each topic is for veterinarians as a Day One competence. Such questions permitted only one answer. The complete questionnaire is available on request from the primary author. These seven questions were the same as those in the questionnaire designed to explore the career preferences of veterinary graduates enrolled in veterinary science programs in Australia and New Zealand (24) (25); (26).

\section{Data Management}

The data were checked for errors, cleaned, and entered into the program $\mathrm{R}$ for ordinal logistic regression analysis. The university employing each educator and the stage of veterinary course taught were ignored, as the number of respondents $(n=142)$ did not allow analysis of these 
variables. For this analysis, the distribution (pattern) of scores for female educators was compared to that for male educators (the factor name in the output was Gender).

Additionally, of the 49 items, four were identified as having a distinct ethics focus. Accordingly, a 0/1 factor (Ethics Subject) was created and used in the analysis to determine whether teaching one or more of these subjects influenced the scores that respondents assigned to the 49 items. The plots in this report are based on the percentages of all scores.

\section{Results}

Of the 550 academic staff members (including clinical, teaching and research staff) who were emailed, 142 participated in the survey, representing an overall participation rate of $25 \%$. There were $72(51 \%)$ female and 70 (49\%) male participants. A detailed analysis of the scores given to each item statement is presented in the sections below. However, a general overview of the following tables (1-7) indicates educators thought there were very important statements in all topics, with the exception of General Practice (for which the lowest score was 3.56).

\section{General Practice}

Educators rated the 10 General Practice topics as shown in Table 1. Professional ethics (the ethical responsibilities of a veterinarian), euthanasia, and triage (having a systematic protocol to establish urgency and severity and differentiate between emergencies and routine cases) were rated as the three most important topics for veterinary graduates to understand on Day One. Understanding the development of animal welfare science and perspectives on welfare were rated as the least important topics for Day One competences (see Table 1). 
Table 1 . Analysis and rankings of General Practice topics assigned by educators ( $n=142)$ at Australian and New Zealand veterinary schools. Ethics subject was a factor used in the analysis to identify respondents who taught subjects with a strong ethics focus.

†

\begin{tabular}{|c|c|c|c|c|}
\hline \multirow[b]{2}{*}{ Topics } & \multirow{2}{*}{$\begin{array}{l}\text { Overall } \\
\text { Ranking } \\
\text { Position } \\
\text { (1 = highest) }\end{array}$} & \multirow[b]{2}{*}{ Mean Rating } & \multicolumn{2}{|c|}{$P$ values for factors } \\
\hline & & & $\begin{array}{l}\text { Gender } \\
\mathbf{d f}=\mathbf{1}\end{array}$ & $\begin{array}{l}\text { Ethics subject } \\
\mathrm{df}=1\end{array}$ \\
\hline $\begin{array}{l}\text { Professional ethics (ethical } \\
\text { responsibilities of a } \\
\text { veterinarian) }\end{array}$ & 1 & 3.56 & 0.536 & 0.678 \\
\hline Euthanasia & 2 & 4.09 & 0.097 & 0.421 \\
\hline $\begin{array}{l}\text { Triage (systematic protocol to } \\
\text { establish urgency and severity } \\
\text { and differentiate between } \\
\text { emergencies and routine cases) }\end{array}$ & 3 & 4.36 & 0.676 & 0.669 \\
\hline $\begin{array}{l}\text { Laws and regulations } \\
\text { regarding animal welfare }\end{array}$ & 4 & 4.71 & 0.968 & 0.595 \\
\hline $\begin{array}{l}\text { Reasons why animal welfare } \\
\text { matters }\end{array}$ & 5 & 5.27 & 0.593 & 0.349 \\
\hline $\begin{array}{l}\text { Science versus values (the } \\
\text { merits of an evidence based } \\
\text { approach velkus one's own } \\
\text { values in making decisions) }\end{array}$ & 6 & 5.55 & 0.606 & 0.112 \\
\hline Applied animal ethics & 7 & 5.78 & $0.046^{*}$ & 0.225 \\
\hline $\begin{array}{lr}\text { Human-animal } & \text { bond (e.g. } \\
\text { strength, } & \text { emotional } \\
\text { attachment) } & \end{array}$ & 8 & 6.07 & 0.656 & 0.944 \\
\hline $\begin{array}{l}\text { Perspectives on welfare (e.g. } \\
\text { intemational/trade, consumer, } \\
\text { marketer, regulator) }\end{array}$ & 9 & 7.28 & 0.383 & 0.371 \\
\hline $\begin{array}{l}\text { The development of animal } \\
\text { welfare science }\end{array}$ & 10 & 8.34 & $0.016^{* *}$ & 0.229 \\
\hline
\end{tabular}

192

193 Place Table 1 here

194 Associations of gender (Gender) and subjects taught (Ethics Subject) with the rating of topics 
The rating of an understanding of the development of animal welfare science was significantly influenced by Gender, with far more female than male educators rating this variable as least important ( $\mathrm{P}=0.016$, Table 1, Figure 1a). The opposite pattern emerged for understanding applied animal ethics, which was rated more important by female than male educators ( $\mathrm{P}=0.046$, Table 1, Figure 1b).

200

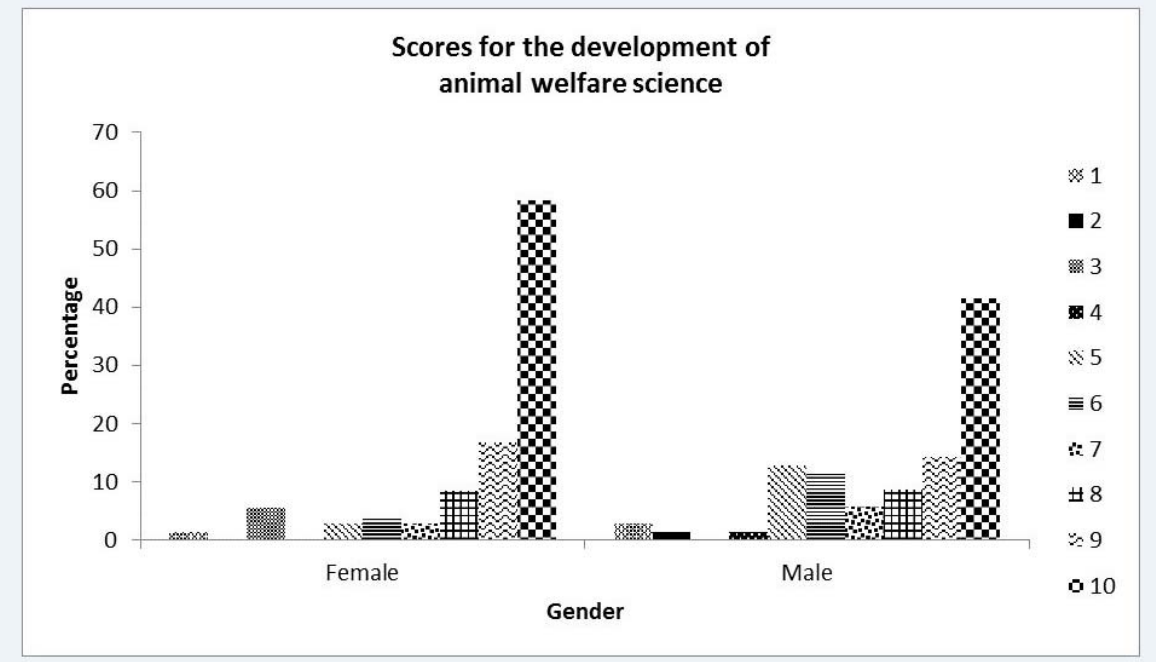

Figure 1a: Gender differences in percentage scores $(n=72$ females; $n=70$ males $)$ for the topic of the development of animal welfare science, with $1=$ extremely important and $10=$ least important. 


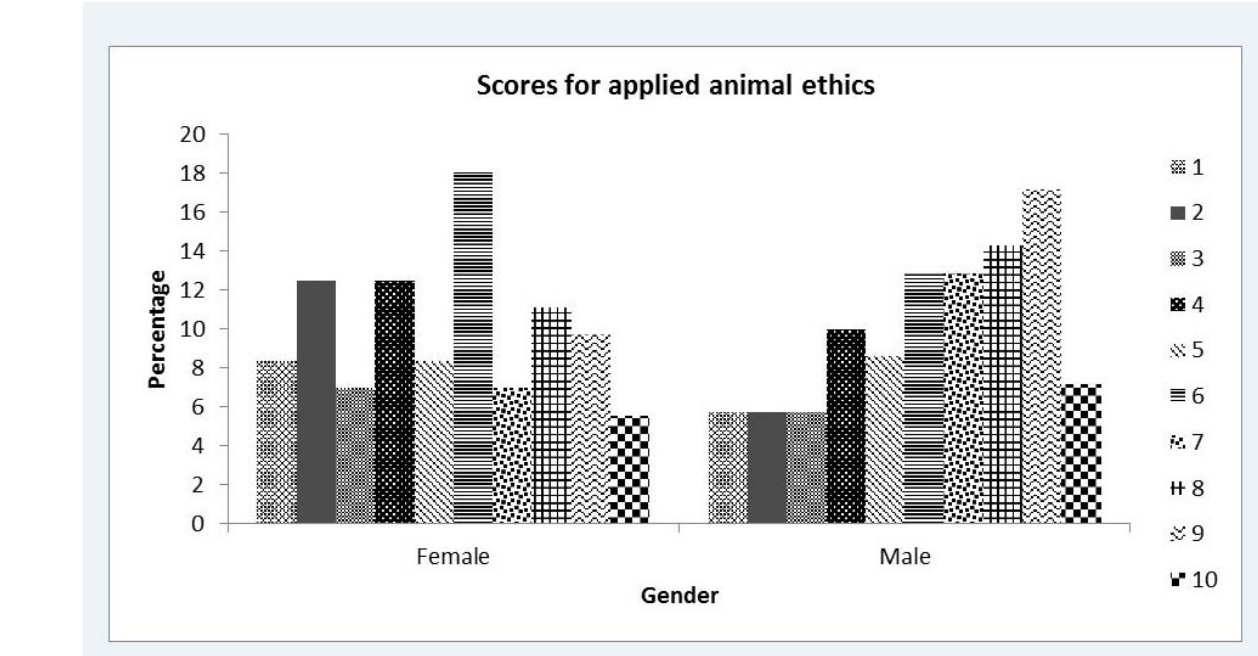

Figure 1b: Gender differences in percentage scores $(n=72$ females; $n=70$ males $)$ for the topic of applied animal ethics, with $1=$ extremely important and $10=$ least important.

\section{Production Animals}

Educators rated the eight Production Animal topics in Question 7 as shown in Table 2. Strategies to address painful husbandry procedures, euthanasia, and the ethics of sustainable production were rated as the three most important topics in which veterinary graduates should be competent on Day One working with Production Animals. Understanding of the social, economic, and cultural drivers of welfare outcomes, and slaughter and pre-slaughter inspections were rated the least important topics for Day One competences in this area. 
Table 2. Analysis and ratings of Production Animal topics assigned by educators ( $n=142)$ at Australian and New Zealand veterinary schools. Ethics Subject was a factor used in the analysis to identify respondents who taught subjects with a strong ethics focus.

$\ddagger$

\begin{tabular}{|c|c|c|c|c|}
\hline \multirow[b]{2}{*}{ Topics } & \multirow{2}{*}{$\begin{array}{l}\text { Overall } \\
\text { Ranking } \\
\text { Position } \\
\text { (1 = highest) }\end{array}$} & \multirow{2}{*}{ Mean Rating } & \multicolumn{2}{|c|}{$P$ values for factors } \\
\hline & & & $\begin{array}{l}\text { Gender } \\
\text { df }=1\end{array}$ & $\begin{array}{l}\text { Ethics Subject } \\
\mathrm{df}=1\end{array}$ \\
\hline $\begin{array}{l}\text { Strategies to address } \\
\text { painful husbandry } \\
\text { procedures }\end{array}$ & 1 & 2.70 & 0.954 & 0.923 \\
\hline Euthanasia & 2 & 3.61 & 0.688 & 0.812 \\
\hline $\begin{array}{l}\text { Ethics of sustainable } \\
\text { production } \\
\text { security, } \\
\text { issues) }\end{array}$ & 3 & 3.98 & 0.610 & 0.253 \\
\hline $\begin{array}{l}\text { Distress associated } \\
\text { with road, sea, and air } \\
\text { transport }\end{array}$ & 4 & 4.65 & 0.288 & 0.922 \\
\hline $\begin{array}{l}\text { Human-animal } \\
\text { interactions and } \\
\text { impacts on animals }\end{array}$ & 5 & 4.72 & $0.009^{888}$ & 0.649 \\
\hline $\begin{array}{lr}\text { Intensive } & \text { versus } \\
\text { extensive } & \text { production } \\
\text { systems } & \end{array}$ & 6 & 4.73 & 0.694 & 0.764 \\
\hline $\begin{array}{l}\text { Social, economic, and } \\
\text { cultural drivers of } \\
\text { welfare outcomes }\end{array}$ & 7 & 5.20 & 0.069 & 0.262 \\
\hline $\begin{array}{l}\text { Slaughter and pre- } \\
\text { slaughter inspections }\end{array}$ & 8 & 5.25 & 0.480 & 0.936 \\
\hline
\end{tabular}

223 Associations of gender (Gender) and subjects taught (Ethics Subject) with the rating of topics

224 There was a significant association with Gender in relation to how educators rated the importance of these topics in that human-animal interactions and impacts on animals was rated 
as more important by female educators than by male educators $(\mathrm{P}=0.009$, Table 2 , Figure 2$)$.

There was no association of subject taught by educators and their rating of topics.

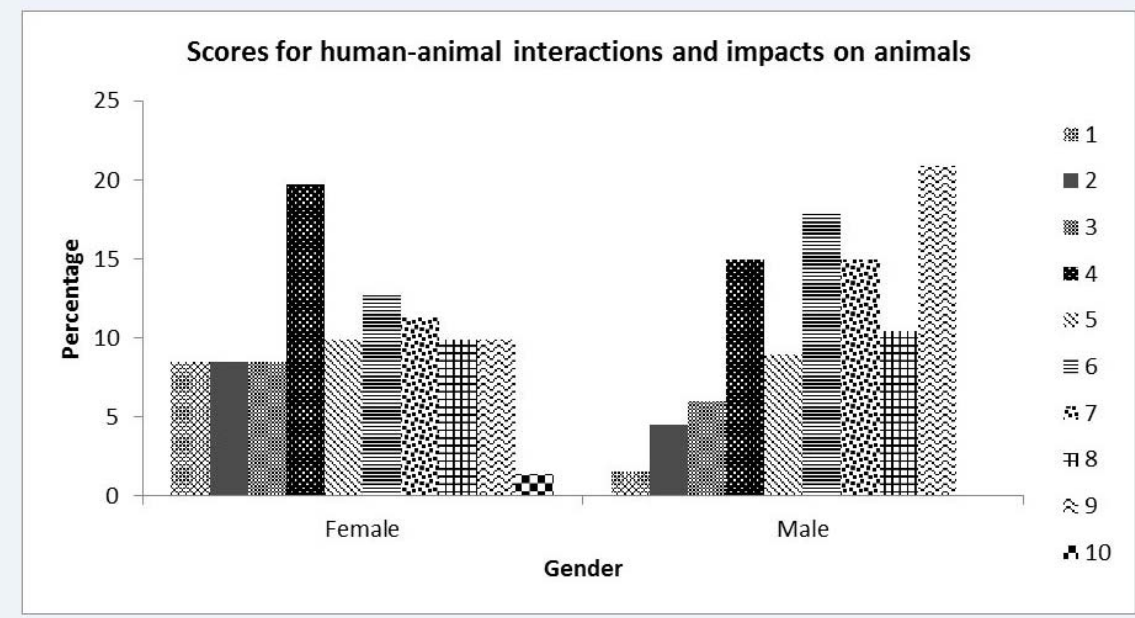

Figure 2: Gender differences in percentage scores $(n=72$ females; $n=70$ males $)$ for the topic of human-animal interactions and impacts on animals, with $1=$ extremely important and $10=$ least important.

Companion Animals

Educators rated the nine Companion Animal topics in Question 8 as shown in Table 3. Euthanasia, companion animal husbandry and neutering were rated as the three most important topics for Day One competence in this area, with behaviour and training being rated a close $4^{\text {th }}$. Understanding over-servicing and cosmetic surgery were rated as the least important topics for Day One competences (Table 3). 
Table 3. Analysis and ratings of Companion Animal topics assigned by educators $(n=142)$ at Australian and New Zealand veterinary schools. Ethics Subject was a factor used in the analysis to identify respondents who taught subjects with a strong ethics focus.

\begin{tabular}{|c|c|c|c|c|}
\hline \multirow[b]{2}{*}{ Topics } & \multirow{2}{*}{$\begin{array}{l}\text { Overall } \\
\text { Ranking } \\
\text { Position } \\
\text { (1 = highest) }\end{array}$} & \multirow{2}{*}{ Mean Rating } & \multicolumn{2}{|c|}{$P$ values for factors } \\
\hline & & & $\begin{array}{l}\text { Gender } \\
\text { df }=1\end{array}$ & $\begin{array}{l}\text { Ethics Subject } \\
\mathrm{df}=\mathbf{l}\end{array}$ \\
\hline Euthanasia & 1 & 2.92 & 0.244 & 0.278 \\
\hline $\begin{array}{l}\text { Companion animal } \\
\text { husbandry }\end{array}$ & 2 & 3.29 & $0.001 * * *$ & 0.468 \\
\hline Neutering & 3 & 3.36 & 0.530 & $0.050 *$ \\
\hline Behaviour and training & 4 & 3.42 & $0.043^{*}$ & 0.112 \\
\hline $\begin{array}{l}\text { Animal } \\
\text { abuse/hoarding }\end{array}$ & 5 & 5.42 & 0.212 & 0.309 \\
\hline Breeding & 6 & 5.79 & 0.618 & 0.438 \\
\hline Shelter medicine & 7 & 6.39 & $0.002 * *$ & 0.359 \\
\hline Over-servicing & 8 & 6.85 & 0.629 & 0.741 \\
\hline Cosmetic surgery & 9 & 7.98 & 0.404 & 0.903 \\
\hline
\end{tabular}

240

241

242

Place Table 3 here

\section{Associations of gender (Gender) and subjects taught (Ethics Subject) with the rating of topics} Gender showed a significant association with how educators rated companion animal husbandry ( $\mathrm{P}=0.001$, Table 3 ) shelter medicine $(\mathrm{P}=0.002$, Table 3$)$, and behaviour and training $(\mathrm{P}=0.043$, Table 3), with far more female educators rating companion animal husbandry and shelter medicine as more important than their male counterparts did (Figures $3 \mathrm{a}$ and $3 \mathrm{~b}$ ). The 
opposite pattern emerged for behaviour and training, which was rated as more important by male than female educators (Figure 3c). An association with subjects taught (Ethics Subject), was significant for neutering $(\mathrm{P}=0.050$, Table 3$)$ in that educators teaching one or more ethics-

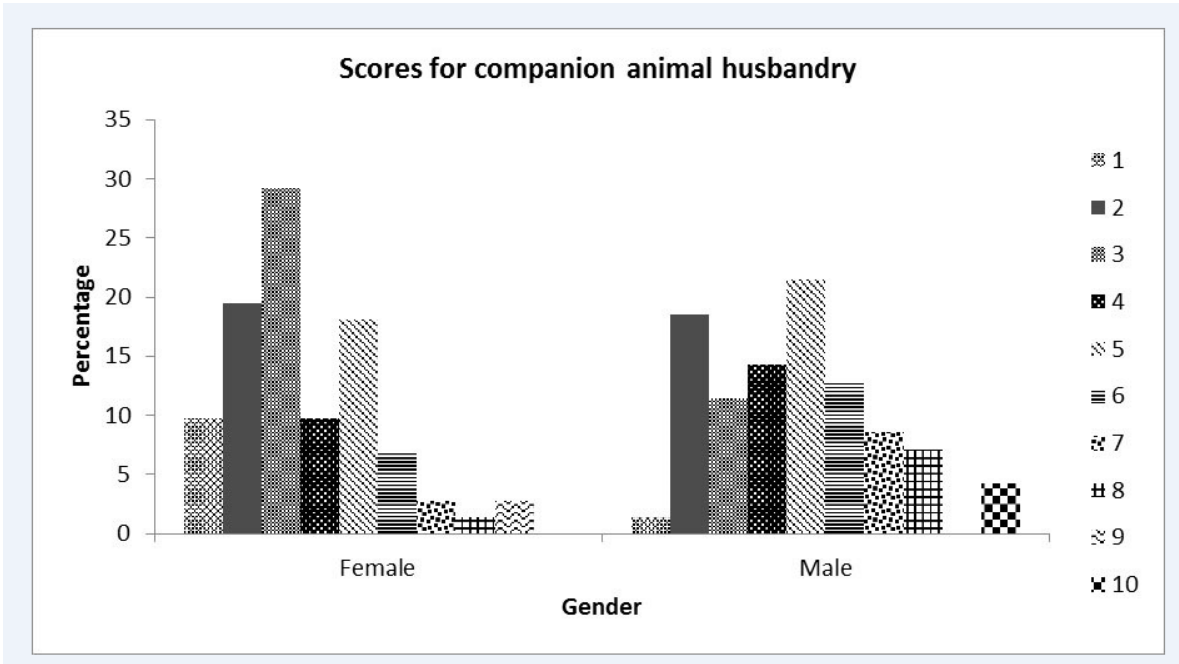

Figure 3a: Gender differences in percentage scores $(n=72$ females; $n=70$ males) for the topic of companion animal husbandry, with $1=$ extremely important and 10=least important. 


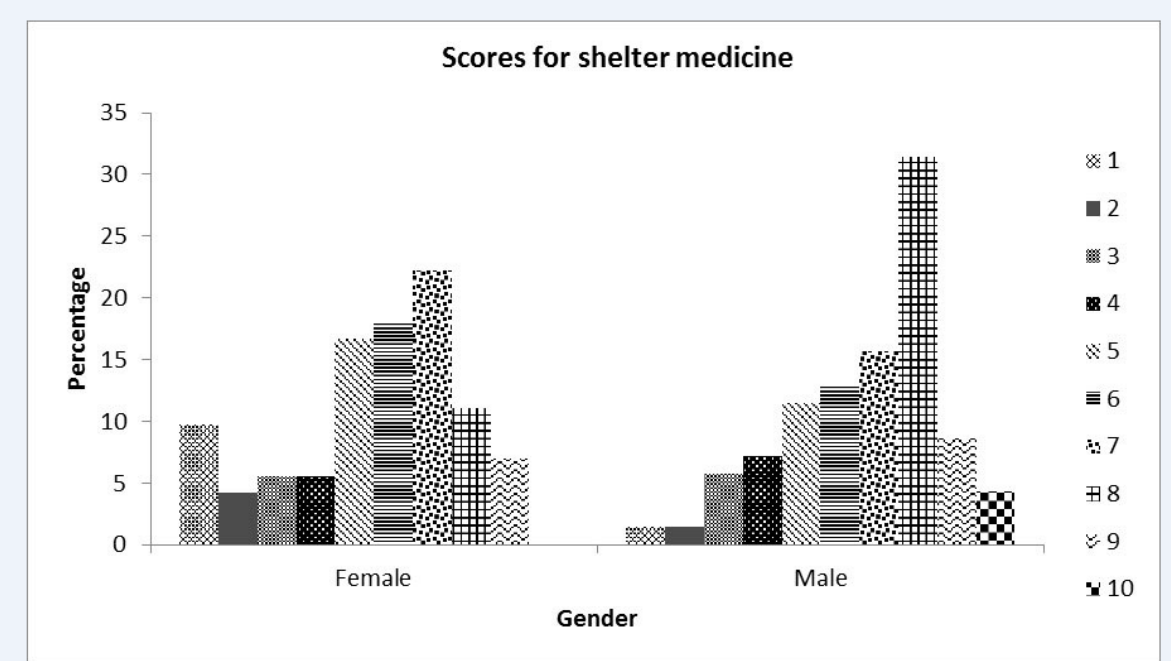

Figure 3b: Gender differences in percentage scores $(n=72$ females; $n=70$ males) for the topic of shelter medicine, with $1=$ extremely important and $10=$ least important.

262

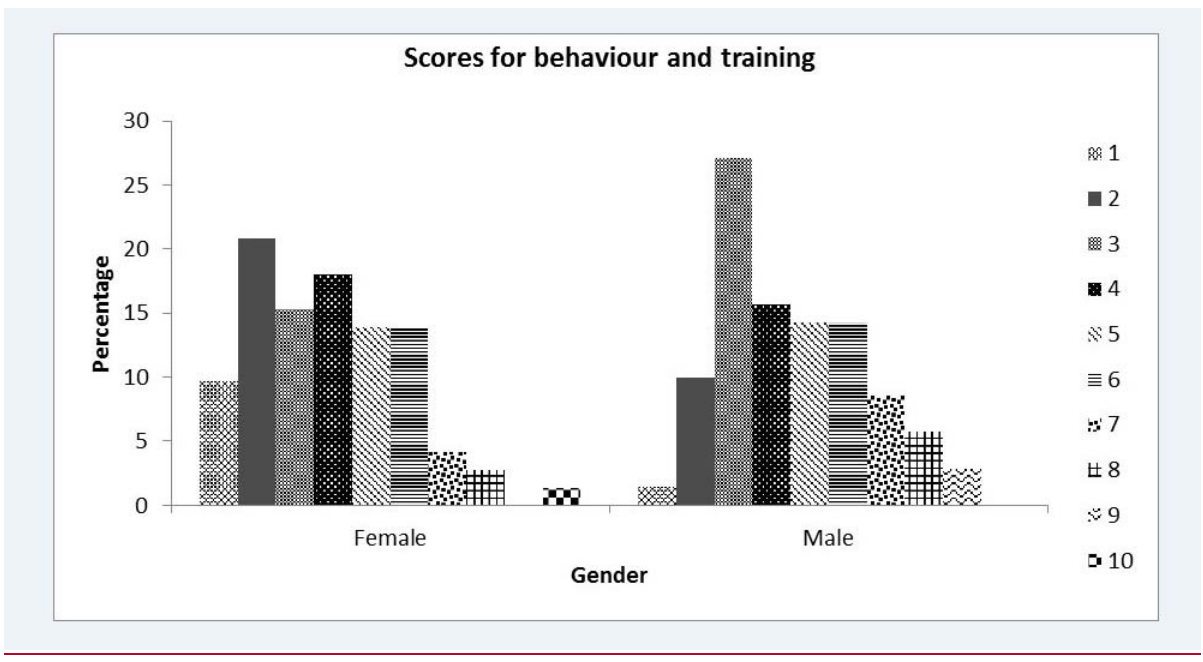

Figure 3c: Gender differences in percentage scores $(n=72$ females; $n=70$ males $)$ for the topic of behaviour and training, with $1=$ extremely important and $10=$ least important. 


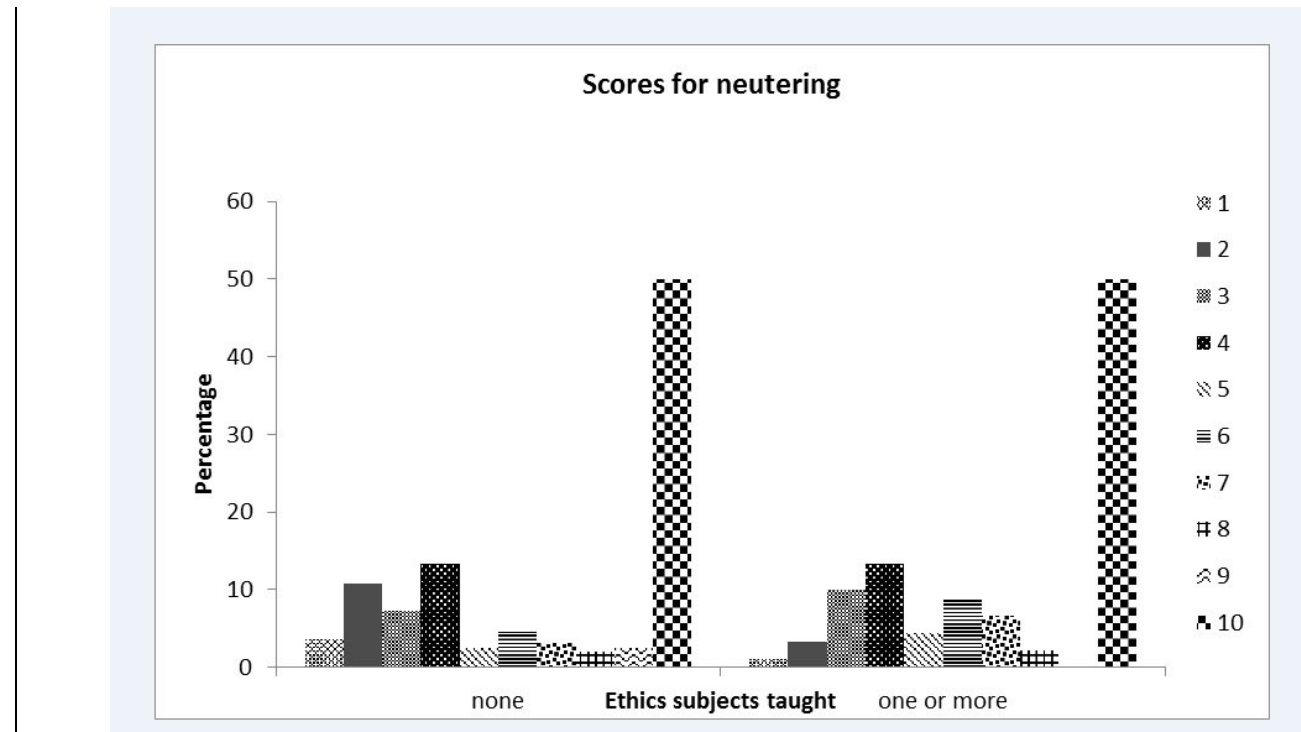

Figure 3d: Effect of subjects taught (Ethics Subject) on percentage scores for the topic of neutering, with $1=$ extremely important and $10=$ least important.

Animals in the Wild

Educators rated the six Animals in the Wild topics in Question 9 as shown in Table 4.

Veterinarians' duties to wild animals and euthanasia were rated as the two most important topics for Day One competence in this area, while understanding tensions between animal welfare and environmental concerns, and methods and justification for wild animal use were rated as the least important topics (Table 4).

276 
Table 4. Analysis and ratings of Animals in the Wild topics assigned by educators ( $n=142$ )

at Australian and New Zealand veterinary schools. Ethics Subject was a factor used in the analysis to identify respondents who taught subjects with a strong ethics focus.

\begin{tabular}{|c|c|c|c|c|}
\hline \multirow[b]{2}{*}{ Topics } & \multirow{2}{*}{$\begin{array}{l}\text { Overall } \\
\text { Ranking } \\
\text { Position } \\
\text { (1 = highest) }\end{array}$} & \multirow{2}{*}{ Mean Rating } & \multicolumn{2}{|c|}{$P$ values for factors } \\
\hline & & & $\begin{array}{l}\text { Gender } \\
\mathrm{df}=1\end{array}$ & $\begin{array}{l}\text { Ethics Subject } \\
\mathrm{df}=1\end{array}$ \\
\hline $\begin{array}{l}\text { Veterinarian's duties } \\
\text { to wild animals }\end{array}$ & 1 & 2.26 & $0.000 * * * *$ & 0.253 \\
\hline Euthanasia & 2 & 2.79 & 0.168 & 0.192 \\
\hline Disaster preparedness & 3 & 4.19 & 0.161 & 0.672 \\
\hline $\begin{array}{l}\text { The nature and state of } \\
\text { semi-owned animals }\end{array}$ & 4 & 4.24 & 0.064 & 0.070 \\
\hline $\begin{array}{l}\text { Tensions between } \\
\text { animal welfare and } \\
\text { environmental } \\
\text { concerns }\end{array}$ & 5 & 4.35 & $0.019 *$ & 0.565 \\
\hline $\begin{array}{l}\text { Methods and } \\
\text { justification for their } \\
\text { uses (e.g. hunting, } \\
\text { wildlife parks) }\end{array}$ & 6 & 4.52 & 0.234 & 0.264 \\
\hline
\end{tabular}

277

Place Table 4 here

\section{Associations of gender (Gender) and subjects taught (Ethics Subject) with the rating of topics}

There was a significant association between Gender and how educators rated the importance of veterinarians' duties to wild animals ( $\mathrm{P}=.000$, Table 4$)$ and tensions between animal welfare and environmental concerns $(\mathrm{P}=.019$, Table 4$)$. A higher proportion of female educators rated these topics as more important than their male colleagues did (Figures $4 \mathrm{a}$ and $4 \mathrm{~b}$ ). There was no association of subject taught with respondents' ratings of topics. 


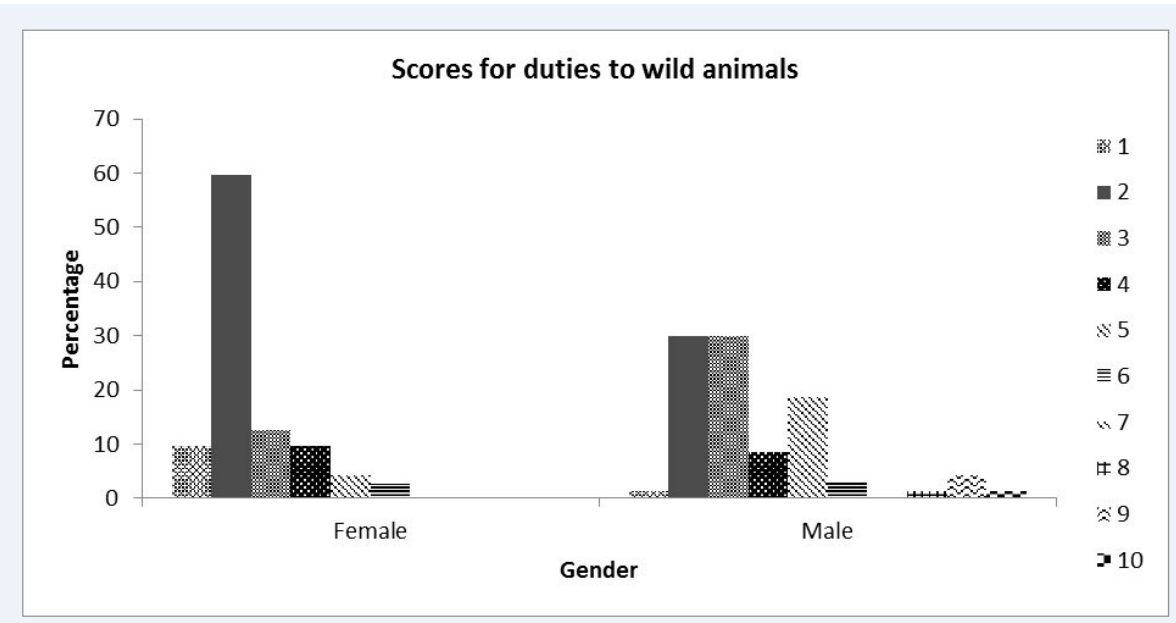

Figure 4a: Gender differences in percentage scores $(n=72$ females; $n=70$ males $)$ for the topic of duties to wild animals, with $1=$ extremely important and $10=$ least important.

290

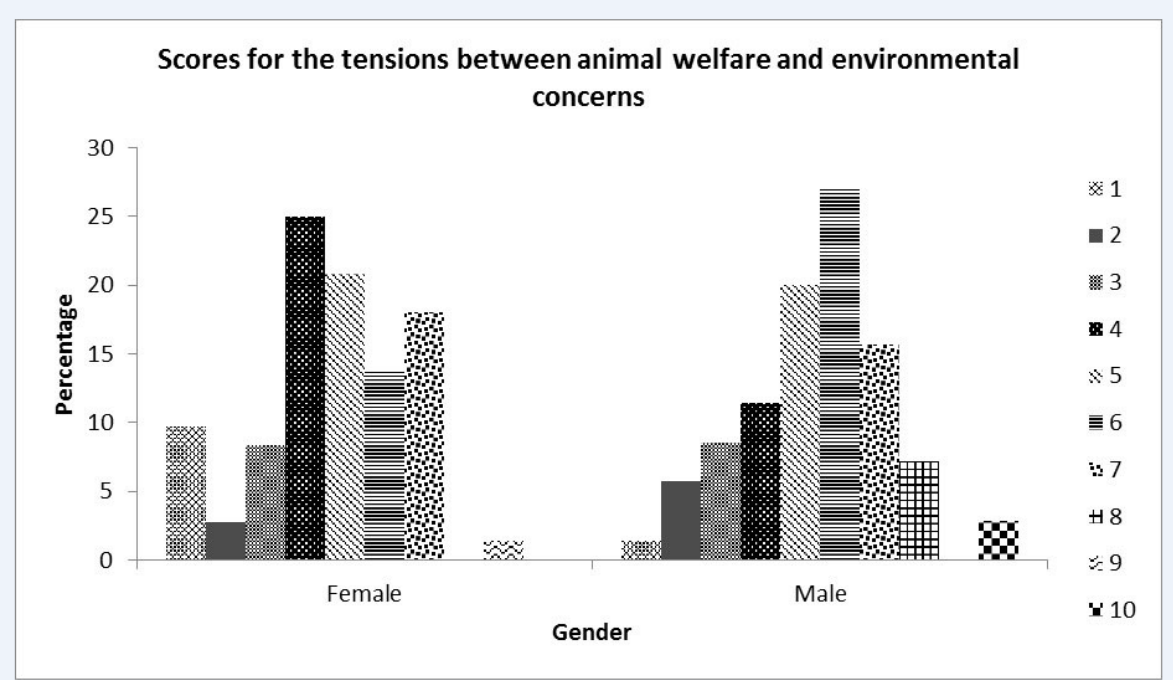

Figure 4b: Gender differences in percentage scores $(n=72$ females; $n=70$ males $)$ for the topic of tensions between animal welfare and environmental concerns, with $1=$ extremely important and $10=$ least important. 


\section{$\underline{\text { Aquatic Animals }}$}

Educators rated the five Aquatic Animals topics in Question 10 as shown in Table 5. Aquatic animal health and welfare issues and husbandry techniques for farmed fish were rated as the two most important Day One competences in this area, while understanding the pain and distress associated with fishing practices and euthanasia were rated as the least important

Table 5. Analysis and ratings of Aquatic Animals topics assigned by educators $(n=142)$ at Australian and New Zealand veterinary schools. Ethics Subject was a factor used in the analysis to identify respondents who taught subjects with a strong ethics focus.

\begin{tabular}{|l|l|l|l|l|}
\hline & $\begin{array}{l}\text { Overall } \\
\text { Tanking } \\
\text { Topics }\end{array}$ & Mean Rating & P values for factors \\
\cline { 4 - 6 } & $\mathbf{P}=\mathbf{\text { highest } )}$ & & $\begin{array}{l}\text { Gender } \\
\mathbf{d f}=\mathbf{1}\end{array}$ & $\begin{array}{l}\text { Ethics Subject } \\
\mathbf{d f}=\mathbf{1}\end{array}$ \\
\hline $\begin{array}{l}\text { Aquatic animal health } \\
\text { and welfare issues }\end{array}$ & 1 & 2.41 & $0.044^{*}$ & 0.461 \\
\hline $\begin{array}{l}\text { Husbandry techniques } \\
\text { of farmed fish }\end{array}$ & 2 & 2.86 & 0.490 & 0.613 \\
\hline $\begin{array}{l}\text { Use of antibiotics } \\
\text { Fishing (pain and } \\
\text { distress associated } \\
\text { with standard angling } \\
\text { and trawling }\end{array}$ & 3 & 3.27 & 0.455 & 0.142 \\
\hline practices) & 4 & 3.50 & $0.001^{* * *}$ & 0.859 \\
\hline \begin{tabular}{l} 
Euthanasia \\
\hline
\end{tabular} & 5 & 4.41 & 0.574 & $0.036 *$ \\
\hline
\end{tabular}

304

Place Table 5 here

Associations of gender (Gender) and subjects taught (Ethics Subject) with the rating of topics 
There were significant associations between Gender and how educators rated the importance of aquatic animal health and welfare issues ( $\mathrm{P}=.044$, Table 5) and fishing (pain and distress associated with standard angling and trawling practices) $(\mathrm{P}=.001$, Table 5), with female educators rating these topics as more important than their males colleagues did (Figures 5a, $5 b)$. There was also a significant effect of subjects taught (Ethics Subject), in that educators teaching one or more ethics related subjects were likely to rate euthanasia as less important (Figure 5c).

315

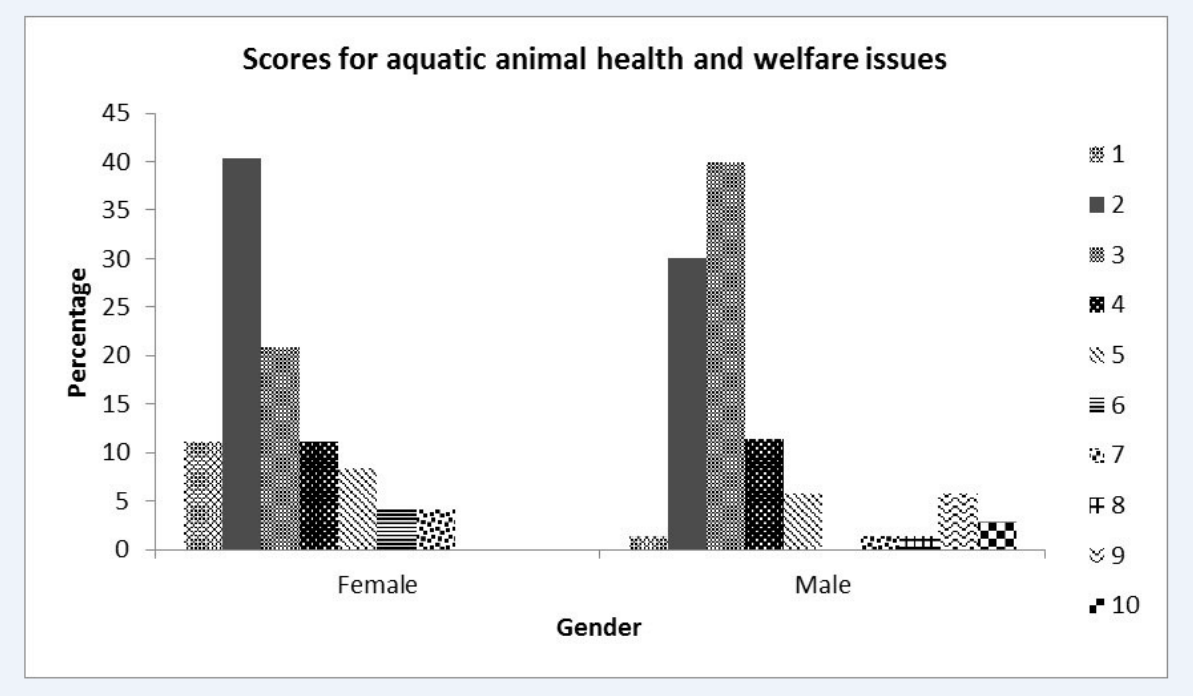

Figure 5a: Gender differences in percentage scores ( $n=72$ females; $n=70$ males) for the topic of aquatic animal health and welfare issues, with $1=$ extremely important and $10=$ least important. 


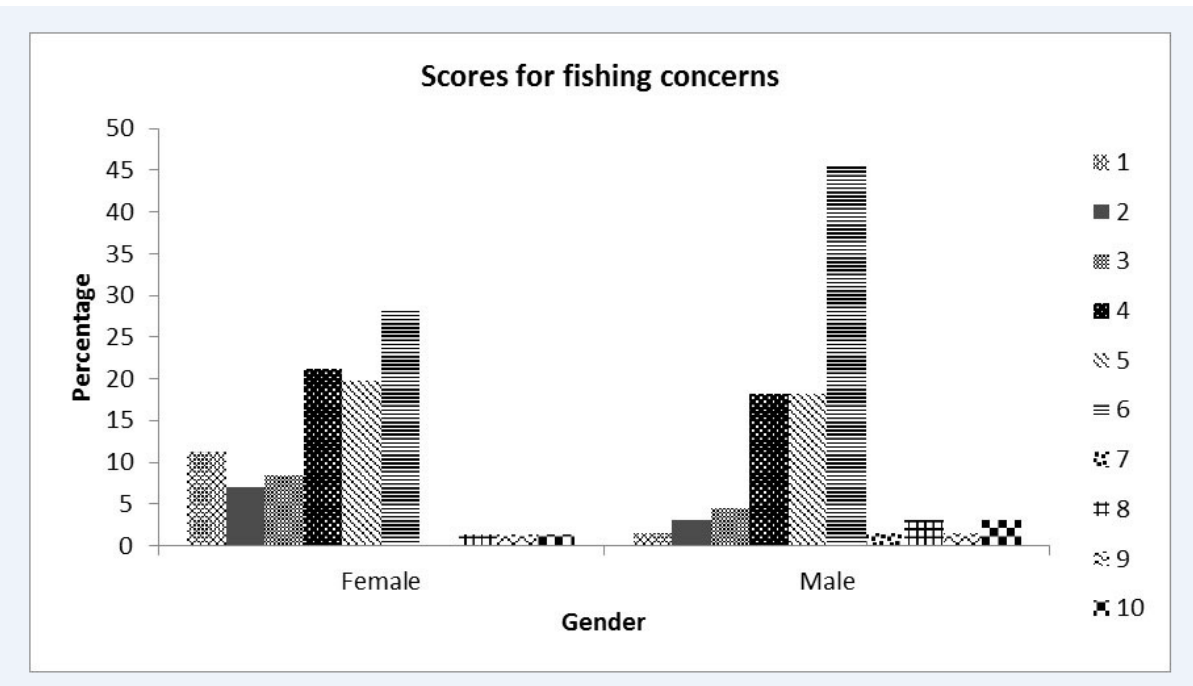

321

325

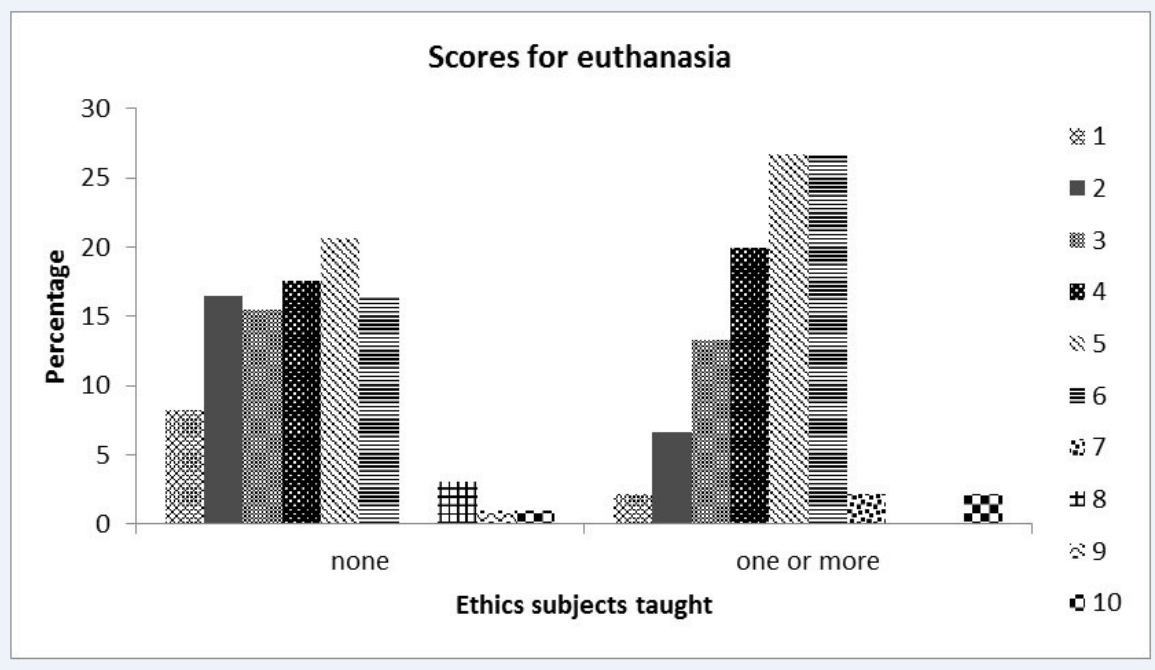

326

327 Figure 5c: Effect of subjects taught (Ethics subject) on percentage scores for the topic of 328 euthanasia, with $1=$ extremely important and $10=$ least important.
Formatted: Justified, Line spacing: 1.5 lines 


\section{Animals Kept for Scientific Purposes}

Educators rated the six topics for Animals Kept for Scientific Purposes in Question 11 as shown

in Table 6. Day One competence in the 3Rs (replacement, refinement, and reduction) and humane endpoints were rated as the two most important topics in this area. Understanding what constitutes a research animal and conscientious objections were rated as the least important Day One competences (Table 6).

Table 6. Analysis and ratings of Animals Kept for Scientific Purposes topics assigned by educators $(n=142)$ at Australian and New Zealand veterinary schools. Ethics Subject was a factor used in the analysis to identify respondents who taught subjects with a strong ethics focus.

\begin{tabular}{|c|c|c|c|c|}
\hline \multirow[b]{2}{*}{ Topics } & \multirow{2}{*}{$\begin{array}{l}\text { Overall } \\
\text { Ranking } \\
\text { Position } \\
\text { (1 = highest) }\end{array}$} & \multirow[b]{2}{*}{ Mean Rating } & \multicolumn{2}{|c|}{$P$ values for factors } \\
\hline & & & $\begin{array}{l}\text { Gender } \\
\text { df }=1\end{array}$ & $\begin{array}{l}\text { Ethics Subject } \\
\text { df }=1\end{array}$ \\
\hline $\begin{array}{l}\text { 3Rs (replacement, } \\
\text { refinement, and } \\
\text { reduction) }\end{array}$ & 1 & 2.93 & 0.357 & 0.762 \\
\hline Humane endpoints & 2 & 3.06 & 0.172 & 0.955 \\
\hline $\begin{array}{l}\text { AEC procedures and } \\
\text { requirements }\end{array}$ & 3 & 3.19 & 0.954 & 0.675 \\
\hline Euthanasia & 4 & 3.31 & 0.213 & 0.694 \\
\hline $\begin{array}{l}\text { What is a research } \\
\text { animal? }\end{array}$ & 5 & 3.84 & $0.029 *$ & 0.053 \\
\hline $\begin{array}{l}\text { Conscientious } \\
\text { objections }\end{array}$ & 6 & 5.28 & $0.028 *$ & 0.718 \\
\hline
\end{tabular}

Place Table 6 here 
342 The effect of Gender on how educators rated the importance of these topics was significant for 343 understanding what constitutes a research animal $(\mathrm{P}=0.029$, Table 6$)$ and conscientious 344 objections ( $\mathrm{P}=0.028$, Table 6$)$, with female educators rating these topics as more important than 345 their males colleagues did (Figures 6a, 6b).
Formatted: Justified, Space After: $0 \mathrm{pt}$, Line spacing: 1.5 lines 


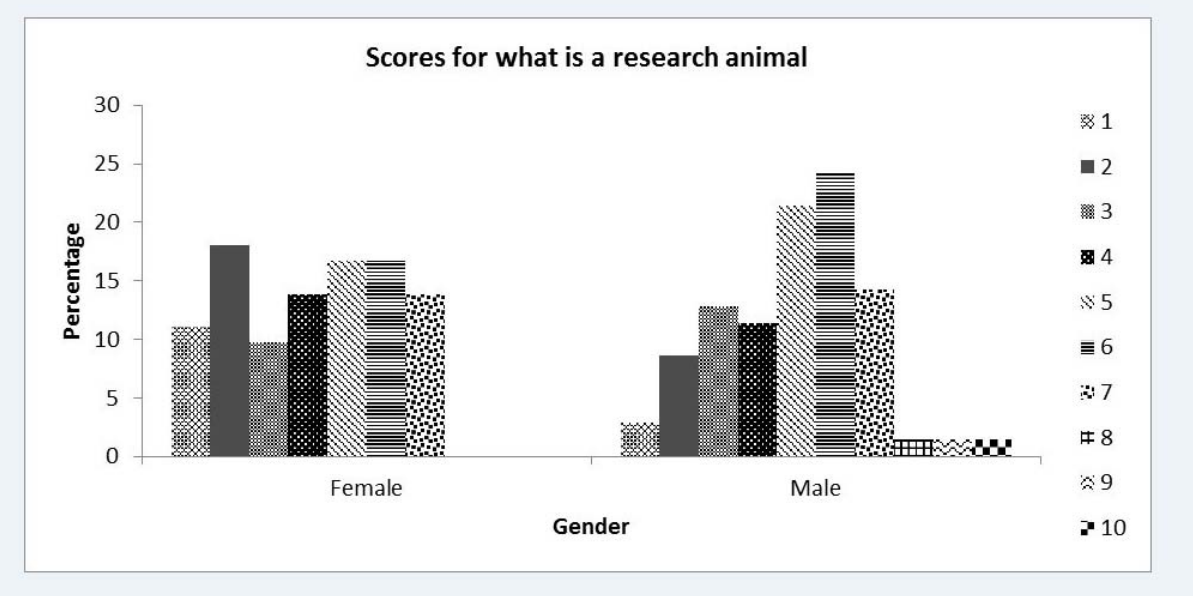

Figure 6a: Gender differences in percentage scores $(n=72$ females; $n=70$ males $)$ for the topic of what is a research animal, with $1=$ extremely important and $10=$ least important.

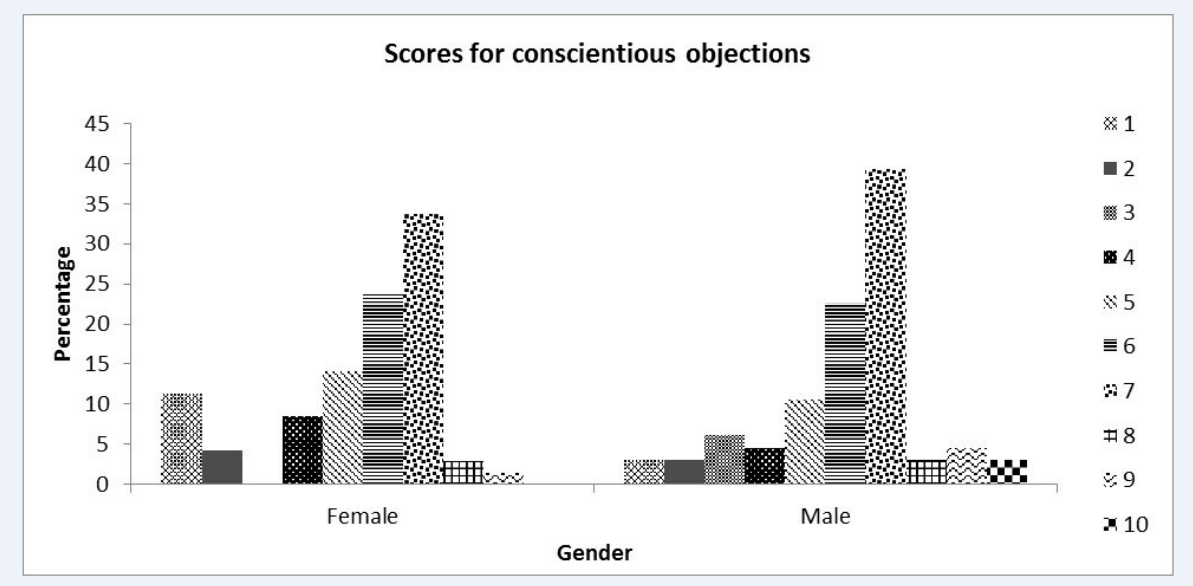

Figure 6b: Gender differences in percentage scores $(n=72$ females; $n=70$ males $)$ for the topic of conscientious objections, with $1=$ extremely important and $10=$ least important. 


\section{Animals Used in Sport and Recreation}

Educators rated the five topics relating to Animals Used in Sport and Recreation in Question 12 as shown in Table 7. The responsibilities of ownership and the effects of pushing of animals to their physical and behavioural limits were rated as the most important topics for Day One competences in this area, while understanding behaviour, selection, and training for sport and

Table 7. Analysis and ratings of Animals Used in Sport and Recreation topics assigned by educators $(\mathrm{n}=142)$ at Australian and New Zealand veterinary schools. Ethics Subject was a factor used in the analysis to identify respondents who taught subjects with a strong ethics focus.

\begin{tabular}{|c|c|c|c|c|}
\hline \multirow[b]{2}{*}{ Topics } & \multirow{2}{*}{$\begin{array}{l}\text { Overall } \\
\text { Ranking } \\
\text { Position } \\
\text { (1 = highest) }\end{array}$} & \multirow{2}{*}{ Mean Rating } & \multicolumn{2}{|c|}{$P$ values for factors } \\
\hline & & & $\begin{array}{l}\text { Gender } \\
\mathbf{d} f=1\end{array}$ & $\begin{array}{l}\text { Ethics Subject } \\
\text { df }=1\end{array}$ \\
\hline $\begin{array}{l}\text { Ownership/ } \\
\text { responsibility }\end{array}$ & 1 & 2.53 & 0.582 & 0.404 \\
\hline $\begin{array}{l}\text { Pushing animals to } \\
\text { physiological/ } \\
\text { behavioural limits }\end{array}$ & 2 & 2.77 & $0.002 * *$ & 0.508 \\
\hline Euthanasia & 3 & 3.09 & 0.501 & 0.106 \\
\hline $\begin{array}{l}\text { Behaviour, selection, } \\
\text { and training for sport } \\
\text { and recreation displays }\end{array}$ & 4 & 3.77 & 0.112 & 0.675 \\
\hline Educating the public & 5 & 3.83 & 0.493 & 0.560 \\
\hline
\end{tabular}

Place Table 7 here

Associations of gender (Gender) and subjects taught (Ethics Subject) with the rating of topics There was a significant association between Gender and how educators rated the importance of understanding these topics as Day One competences, with female educators rating pushing 
371 animals to their physiological / behavioural limits as more important than their males

372 colleagues did $(\mathrm{P}=.002$, Table 7, Figure 7).

373 


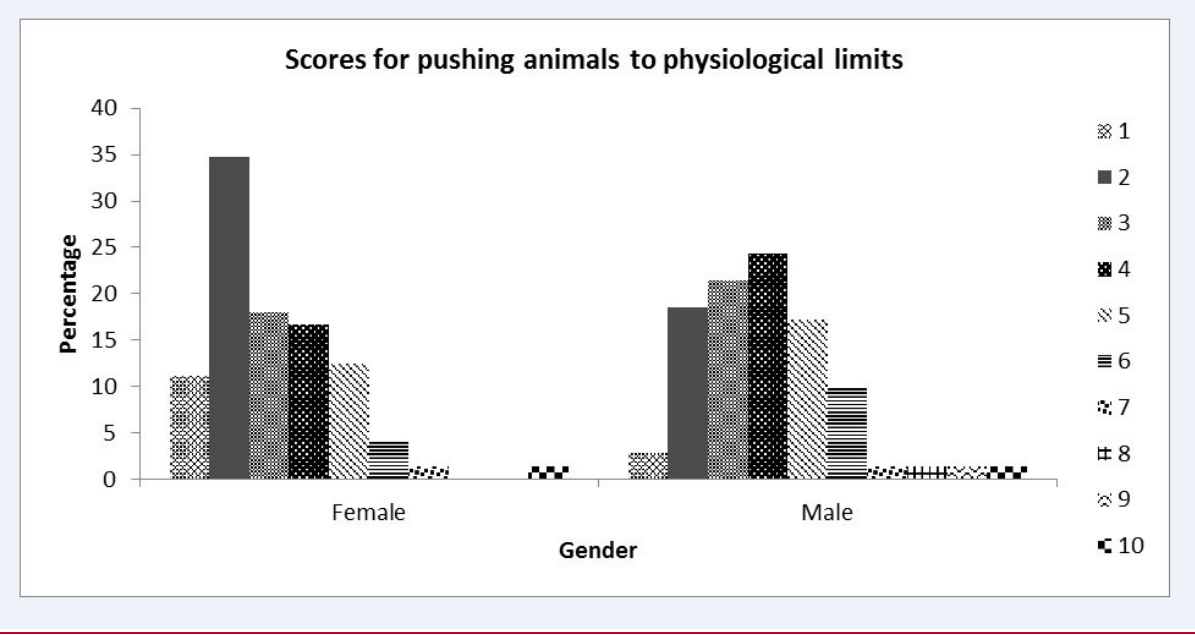

Figure 7: Gender differences in percentage scores $(n=72$ females; $n=70$ males $)$ for the topic of pushing animals to their physiological / behavioural limits, with 1=extremely important and $\mathbf{1 0}=$ least important.

\section{Discussion}

This study provides valuable insights into how veterinary educators rate the importance of various AWE topics as Day One competences for veterinary graduates. For some topics, the assigned ratings showed associations with the educator's gender and whether they taught subjects with a strong focus on ethics. For example, far more female than male educators rated the development of animal welfare science as least important. Such associations among the current findings must be treated with some caution given the small sample size and the lack of any data on the gender distribution in educators throughout the schools we sampled. Nevertheless, the current findings serve to remind us that our predispositions to favour certain topics may reflect our gender and familiarity with particular subjects. As the relative importance of AWE looks set to rise (7), veterinary schools need to decide how to prioritise various elements of the AWE curriculum. 
When considering General Practice, veterinary educators rated professional ethics, euthanasia and triage as the most important Day One competences. These topics reflect the risk of Day One graduates being presented with dilemmas and scenarios that demand complex scientific, ethical, and communication skills. Plainly, ethical dilemmas are common in veterinary practice (27). A recent UK study revealed that the training of veterinary students in ethical decisionmaking was inadequate and that the shortfall in this aspect of veterinary education contributed to workplace stress (28). Given that several studies have suggested that female veterinarians may be at greater risk of stress than their male colleagues (29) (28) (30), the ongoing feminisation of the veterinary profession should underline the need for more and better training in ethical decision-making.

In contrast, understanding perspectives on welfare and the development of animal welfare science were rated as least important by veterinary educators as Day One competences. The low rating of the latter topic is of concern, given veterinarians are routinely expected to make critical AWE decisions, based on science and community expectations. However, it is possible that the phrasing of this topic gave educators the impression they were assessing the merits of a theoretical understanding of perspectives on welfare or the development of animal welfare science rather than the benefits of a scientific approach to welfare. These results are similar to those from a parallel survey of students (26).

\section{Production Animals}

Strategies to address painful husbandry procedures, euthanasia and the ethics of sustainable production were rated as the three most important Day One competences in the area of Production Animals. Controlling pain and ending life are core to the expertise of those in the production sector so their importance is unsurprising. That said, there is some evidence that veterinary practitioners vary in their opinions towards production animal welfare (31). Given the current world focus on climate change, food biosecurity, and the welfare of production animals, especially in intensive systems, it is also not surprising that veterinary educators rated an understanding of the ethics of sustainable production highly as a Day One competence. As the subjects that educators taught had no significant bearing on the priority given to this topic, we can assume that support for this view was shared across the different areas of teaching. Understanding of the social, economic and cultural drivers of welfare outcomes, and slaughter 
and pre-slaughter inspections were rated as the least important topics for Day One competences. It may be that educators think these are important topics but not as priorities for Day One competences. This should be investigated further.

\section{Companion Animals}

The results of this survey suggest that veterinary educators in Australia and New Zealand prioritise AWE topics that directly relate to the wellbeing of individual patients and their owners rather than ones that may seem more esoteric or abstract, e.g. which involve broader social structures or poor professional conduct. Routine matters and procedures such as euthanasia, good husbandry, neutering, and behaviour and training were rated highly as Day One competences. These ratings reflect the everyday need for veterinarians to be conversant in these topics in order to give good advice to clients. Over servicing, cosmetic surgery and shelter medicine were rated as least important as Day One competences, as also found in a parallel student survey (25). This may suggest that students mirror the views of the educators teaching them, but any attempt to ascribe causality will require further investigation.

\section{Animals in the Wild}

Veterinarians' duties to wild animals and euthanasia were rated as the two most important Day One competences for graduates working with animals in the wild. Graduates may be called upon by law enforcement officers to administer assistance to wild animals in public situations or to euthanase injured wild animals. The need to act with confidence in these circumstances is reflected in the current ratings. Understanding tensions between animal welfare and environmental concerns, and methods and justification for wild animal uses were rated as the least important Day One competences. This may be because these topics suggest a theoretical or philosophical approach and as such may have been regarded by educators as having little relevance to Day One graduates. These findings mirror those of a parallel survey of veterinary students (32). It appears that topics that demand theoretical or philosophical approach in the classroom may be avoided in preference given to topics that relate directly to practical skills. If theoretical or philosophical material is assessed, then they will have less uptake than practical skills because students know clients will not judge them on their ability to discuss the finer points of an ethics debate. In contrast, if students cannot perform routine procedures, they will neither pass their exams nor get a job. Given the calls for veterinarians to engage more actively 
in animal ethics debate, this finding may trigger further review of faculties' commitment to the teaching of animal ethics.

\section{Aquatic Animals}

All Aquatic Animal topics were rated as being of high to moderately high importance as Day One competences, with Aquatic animal health and welfare issues and husbandry techniques for farmed fish rated as the two most important topics. The overall ratings suggest that educators saw the fish farming industry, with the concomitant use of antibiotics, as being more relevant to new graduates than the angling or trawling industries. This suggests the need for more work in this area for veterinarians.

Understanding the pain and distress associated with fishing practices and euthanasia were seen as the least important topics as Day One competences. -This is somewhat surprising given the contentious nature of these topics. There was significant association between Gender and how educators rated the importance of aquatic animal health and welfare issues and for fishing procedures as Day One competences with female educators rating these topics as more important than their male colleagues did. Similar findings were reported when the questionnaire was completed by veterinary students (24), (unpublished data). Additionally, educators teaching one or more ethics related subjects were likely to rate euthanasia as less important. This rating is rather surprising, given that the humane killing of animals is a core veterinary duty, and that vets must be able to counsel owners around the decision to euthanase and then administer this procedure effectively and safely. It may be that most educators have not been exposed to the euthanasia of pet or ornamental fish because so few clients present moribund fish to veterinarians for this procedure. The lack of demand for veterinary administered euthanasia in these animals could be a reflection of a perceived lack of skills in fish health among veterinarians or the reality that many ornamental fish are inexpensive to replace (33).

\section{Animals Kept for Scientific Purposes}

Formatted: Font color: Auto 
All topics relating to Animals Kept for Scientific Purposes were rated by educators as being of high to medium importance as Day One competences, and in this regard were similar to the parallel student survey (unpublished data).

Competence in the 3Rs (replacement, refinement and reduction) and humane endpoints were rated as the two most important Day One competences for graduates working in this area. Our results suggest that educators and veterinary students recognise the anticipated importance of these issues immediately upon graduation. These considerations are central to teaching around the practice of animal ethics committees in in Australia and New Zealand. It is worth noting that there are innovations that will reduce the use of animals in veterinary teaching (e.g., (34) and calls to expand the 3 Rs to the 4Rs to include rehabilitation (of animals after their use) (35). Future studies that revisit the current research questions may reveal how these innovations are being received by veterinary educators.

Understanding what constitutes a research animal and conscientious objections were rated as the least important Day One competences in this area. The effect of Gender on how educators rated the importance of these topics was significant for what constitutes a research animal and conscientious objections, with female educators rating these as more important than their male colleagues did. It is unclear whether these findings reflects a gender bias in the proportion of veterinary science educators who have sat on institutional animal ethics committees and therefore appreciate the impact of these apparent subtleties.

\section{Animals Used in Sport and Recreation}

The responsibilities of ownership and the pushing of animals to their physical and behavioural limits were rated by educators as the most important topics for Day One competences in the area of Animals used in Sport and Recreation. There was a significant association between Gender and how educators rated these topics, with female educators rating pushing animals to their physiological / behavioural limits as more important than their male colleagues did. This finding aligns with previous studies that have shown better female awareness of not causing animals to suffer (14).

Educators rated the responsibilities of ownership as the most important issue confronted by newly graduated veterinarians. In contrast, the students who completed the questionnaire were 
not strongly concerned about this issue (unpublished data). It is not clear what may be driving this apparent difference. The concept of responsibility of ownership comes with age and perhaps students cannot be expected to understand this.

Euthanasia rated in the middle. Euthanasing animals used for work, sport, recreation and display may occur in public under extreme circumstances but is more commonly the result of extended consultation with owners. The euthanasia of healthy animals can be a challenge for veterinarians (36) but retirement homes for animals from work, sport, recreation and display roles can be hard to find (37). If old age or injury or mean that animals can no longer perform the roles for which they are kept, then euthanasia is a common course of action (37). Fewer emotional considerations seem to pertain than, for example, in the contexts of companion animals. So, veterinary educators must help students to understand that commercial pressures often drive owners' requests for euthanasia of healthy work, sport, recreation and display animals.

\section{Conclusions}

The rating of these topics by educators was very similar to those by undergraduate veterinary science students who completed the same questionnaire $(24-26,32)$. The educators' focus on practical issues and avoidance of esoteric issues clashes with a perceived need for veterinarians to embrace animal ethics more actively. Overall, results are in keeping with previous research that suggests that women are more likely to show empathy towards some animals than men, and men were less concerned with questions of animal welfare.

\section{Acknowledgements}

Support for this publication has been provided by the Australian Government Office for Learning and Teaching. The views in this publication do not necessarily reflect the views of the Australian Government Office for Learning and Teaching. 


\section{References}

1. Crook A. The CVMA animal abuse position--how we got here. Can Vet J. 2000;41(8):631-5.

2. Friend TH. Teaching animal welfare in the land grant universities. J Anim Sci. 1990;68(10):3462-7.

3. Izmirli S, Phillips CJ. Attitudes of Australian and Turkish veterinary faculty toward animal welfare. J 4 Vet Med Educ. 2012;39(2):200-7.

4. Hewson CJ, Baranyiová E, Broom DM, Cockram MS, Galindo F, Hanlon AJ, et al. Approaches to teaching animal welfare at 13 veterinary schools worldwide. J Vet Med Educ. 2005;32(4):422-37.

5. McGreevy PD, Dixon RJ. Teaching animal welfare at the University of Sydney's Faculty of Veterinary

Science. J Vet Med Educ. 2005;32(4):442-6.

6. Stafford K. Animal Welfare in New Zealand. ...Palmerston North: New Zealand Society of Animal Production; 2013.

7. $\quad$ BVA. Vets speaking up for animal

welfare: BVA animal welfare strategy. 2016 [Available from: https://www.bva.co.uk/uploadedFiles/Content/News, campaigns and policies/Policies/Ethics and we lfare/BVA-animal-welfare-strategy-feb-2016.pdf.

8. Broom DM. Animal welfare education: development and prospects. J Vet Med Educ. 2005;32(4):43841.

9. RCVS. RCVS Day one competences 2014 [Available from: https://www.rcvs.org.uk/document-

library/day-one-competences/.

10. FVE, EAEVE. FVE \& EAEVE. - Report on European -veterinary -education -in -animal -welfare -science, ethics -and law. 2013 [Available from:

http://www.fve.org/uploads/publications/docs/full report aw curriculum adopted.pdf.

11. Fawcett A. Veterinary associations prioritise animal welfare. The Veterinarian. 2016.

12. Dohoo SE, Dohoo IR. Factors influencing the postoperative use of analgesics in dogs and cats by Canadian veterinarians. Can Vet J. 1996;37(9):552-6.

13. Dohoo SE, Dohoo IR. Postoperative use of analgesics in dogs and cats by Canadian veterinarians. Can Vet J. 1996;37(9):546-51.

14. Paul ES, Podberscek AL. Veterinary education and students' attitudes towards animal welfare. Vet Rec. 2000;146(10):269-72.

15. Levine ED, Mills DS, Houpt KA. Attitudes of veterinary students at one US college toward factors relating to farm animal welfare. J Vet Med Educ. 2005;32(4):481-90.

16. Serpell JA. Factors influencing veterinary students career choices and attitudes to animals. J Vet Med Educ. 2005;32(4):491-6.

17. Pollard-Williams S, Doyle RE, Freire R. The influence of workplace learning on attitudes toward animal welfare in veterinary students. J Vet Med Educ. 2014;41(3):253-7.

18. Verrinder JM, Phillips CJ. Development of a moral judgment measure for veterinary education. J Vet Med Educ. 2014;41(3):258-64.

19. Verrinder JM, Phillips CJ. Identifying veterinary students' capacity for moral behavior concerning animal ethics issues. J Vet Med Educ. 2014;41(4):358-70.

20. Verrinder JM, Phillips CJ. Assessing Veterinary and Animal Science Students' Moral Judgment Development on Animal Ethics Issues. J Vet Med Educ. 2015;42(3):206-16.

21. Verrinder JM, Ostini R, Phillips CJ. Differences in Moral Judgment on Animal and Human Ethics Issues between University Students in Animal-Related, Human Medical and Arts Programs. PLoS One. 2016;11(3): 0149308.

22. Robinson D, Williams M, Buzzeo J. RCVS survey of the veterinary professions 2014 synthesis report . UK: Institute of Employment Studies; 2014.

23. Heleski CR, Mertig AG, Zanella AJ. Results of a national survey of US veterinary college faculty regarding attitudes toward farm animal welfare. J Am Vet Med Assoc. 2005;226(9):1538-46.

24. Cornish AR, Caspar GL, Collins T, Degeling C, Fawcett A, Fisher AD, et al. Career Preferences and Opinions on Animal Welfare and Ethics: A Survey of Veterinary Students in Australia and New Zealand. J Vet Med Educ. 2016;43(3):310-20.

25. Degeling C, Fawcett A, Collins T, Hazel S, Johnson J, Lloyd J, et al. Students' opinions on welfare and ethics issues for companion animals in

Australian and New Zealand veterinary schools. Australian Veterinary

Journal In press.
Formatted: Font: $10 \mathrm{pt}$

Formatted: Left

Formatted: Font: $10 \mathrm{pt}$

Formatted: Left, Indent: Left: 0", Hanging: 0.5"

Formatted: Left, Space After: $0 \mathrm{pt}$

Formatted: Left, Indent: Left: 0", Hanging: 0.5"

Formatted: Left, Space After: $0 \mathrm{pt}$

Formatted: Left, Indent: Left: 0", Hanging: 0.5", Space After: $0 \mathrm{pt}$

Formatted: Left

Formatted: Left, Indent: Left: 0", Hanging: 0.5" 
26. Freire R, Phillips CJ, Verrinder JM, Collins T, Degeling C, Fawcett A, et al. The Importance of Animal Welfare Science and Ethics to Veterinary Students in Australia and New Zealand. J Vet Med Educ. 2016:1-9.

27. Johnson J, Collins T, Degeling C, Fawcett A, Fisher AD, Freire R, et al. The First Shared Online Curriculum Resources for Veterinary Undergraduate Learning and Teaching in Animal Welfare and Ethics in Australia and New Zealand. Animals (Basel). 2015;5(2):395-406.

28. Batchelor CE, McKeegan DE. Survey of the frequency and perceived stressfulness of ethical dilemmas encountered in UK veterinary practice. Vet Rec. 2012;170(1):19.

29. Gardner DH, Hini D. Work-related stress in the veterinary profession in New Zealand. N Z Vet J. 2006;54(3):119-24.

30. Platt B, Hawton K, Simkin S, Mellanby RJ. Suicidal behaviour and psychosocial problems in veterinary surgeons: a systematic review. Soc Psychiatry Psychiatr Epidemiol. 2012;47(2):223-40.

31. Heise H, Kemper N, Theuvsen L. [The attitude of German veterinarians towards farm animal welfare: results of a cluster analysis]. Berl Munch Tierarztl Wochenschr. 2016;129(5-6):225-33.

32. Stafford K, Collins T, Degeling C, Freire R, Hazel S, Johnson J, et al. Veterinary students' opinions on their required

competence in dealing with welfare and ethics issues pertaining to wild animals. Journal of Zoo and Wildlife Medicine. In press.

33. Walster C, Rasidi E, Saint-Erne N, Loh R. The welfare of ornamental fish in the home aquarium. Companion Animal. 2015;20(5):302-6.

34. Gopinath D, McGreevy PD, Zuber RM, Klupiec C, Baguley J, Barrs VR. Developments in undergraduate teaching of small-animal soft-tissue surgical skills at the University of Sydney. J Vet Med Educ. 2012;39(1):21-9.

35. Badyal DK, Desai C. Animal use in pharmacology education and research: the changing scenario. Indian J Pharmacol. 2014;46(3):257-65.

36. Tran L, Crane MF, Phillips JK. The distinct role of performing euthanasia on depression and suicide in veterinarians. J Occup Health Psychol. 2014;19(2):123-32.

37. Thomson PC, Hayek AR, Jones B, Evans DL, McGreevy PD. Number, causes and destinations of horses leaving the Australian Thoroughbred and Standardbred racing industries. Aust Vet J. 2014;92(8):303-11 